\title{
Brief Communication: Understanding disasters and early-warning systems
}

\author{
H. Castaños ${ }^{1}$ and C. Lomnitz ${ }^{2}$ \\ ${ }^{1}$ Instituto de Investigaciones Económicas, Universidad Nacional Autónoma de México, \\ 04510 Mexico, DF, Mexico \\ ${ }^{2}$ Instituto de Geofísica, Universidad Nacional Autónoma de México, \\ 04510 Mexico, DF, Mexico \\ Correspondence to: C. Lomnitz (cinna@ prodigy.net.mx)
}

Received: 10 January 2014 - Published in Nat. Hazards Earth Syst. Sci. Discuss.: 1 August 2014

Revised: - Accepted: 1 November 2014 - Published: 18 December 2014

\begin{abstract}
This paper discusses some methodological questions on understanding disasters. Destructive earthquakes continue to claim thousands of lives. Tsunamis may be caused by recoil of the upper plate. Darwin's twin-epicenter hypothesis is applied to a theory of tsunamis. The ergodicity hypothesis may help to estimate the return periods of extremely rare events. A social science outline on the causation of the Tôhoku nuclear disaster is provided.
\end{abstract}

\section{Introduction}

Early warning systems have much in common with disaster prevention. The 2011 Fukushima accident showed that redundancy can be a double-edged sword: it increases the complexity of a system without necessarily improving its performance. It is unrealistic to assume zero defects in backup systems (Feiler, 2013).

The Fukushima Dai-ichi nuclear power plant was located in a typical coastal landscape. There were many flat-topped marine terraces about $25 \mathrm{~m}$ high. One of these terraces was selected for situating the nuclear plant. Boiling-water reactors are vulnerable to a combination of station blackout and loss-of-coolant accident. The 11 March 2011 Tôhoku megaquake of magnitude 9.0 contributed to the collapse of an aging power grid. Eleven nuclear reactors scrammed simultaneously, thus causing a peak in demand. Power could not be borrowed from neighboring grids because the Tôhoku grid was on $50 \mathrm{~Hz}$. Mobile generators failed to reach the stricken plant because of landslides in access roads. Tower 27 of the
$66 \mathrm{kV}$ Yonomori line to Tokyo collapsed in the earthquake, and repair took about a week because of the high levels of radiation.

Fukushima I was owned by the Tokyo Electric Power Company. The plant had six reactors, but only units 1, 2 and 3 were on stream at the time of the accident. The tsunami caused irreparable damage to 12 backup diesel generators that were running in the basement of the turbine building. The sea level dropped below the level of the seawater inlets, and the seawater pumps broke down. Successive hydrogen explosions blew off the containment structures of reactors 1 , 2 and 3. Meltdown: the population was evacuated.

The design philosophy of Fukushima I relied on multiple, redundant, diverse and independent safety features: diesel generators, batteries and pumps placed at different levels around the reactors. A more recent design approach is known as the reliability validation and improvement framework (VFIF). It bases design requirements on four pillars of operational scenarios (Feiler, 2013).

In addition, at least two nations installed waterproof backup diesel generators in their seaside nuclear power plants (Lipscy et al., 2013). A station blackout occurred on 29 October 2012, in a boiling-water reactor at the Oyster Creek, New Jersey plant. The grid collapsed in Hurricane Sandy, and the backup generators were flooded, but the generators were waterproof. 


\section{Early warning systems}

Early warning systems have built-in blind spots. Let $b$ be the distance from the epicenter to an observer on the land, and consider warnings that can be received ahead of the $\mathrm{S}$ wave arrival. Then, a simple estimate of the efficacy of an early warning system may be written as follows (Kuyuk and Allen, 2013):

$b=\sqrt{\left(t_{\mathrm{P}}+t_{\mathrm{D}}\right)^{2} V_{\mathrm{S}}^{2}-D^{2}}$,

where $t_{\mathrm{P}}$ is the delay caused by detection of the $\mathrm{P}$ wave signal by at least four nearby stations, $t_{\mathrm{D}}$ is the delay caused by processing of the four $\mathrm{P}$ wave signals, $V_{\mathrm{S}}$ is the velocity of propagation of $\mathrm{S}$ waves, and $D$ is the focal depth of the earthquake. Note that $S$ waves and surface waves are expected to cause most of the damage and that these waves are slower than $P$ waves. If an early warning is to be useful, it must be received ahead of the $\mathrm{S}$ wave arrival, otherwise there is no point in the exercise.

However, $b$ is the minimum epicentral distance such that the warning will arrive ahead of the $\mathrm{S}$ wave, given $b$ greater than 0 . Otherwise, the warning will be too late to be of any use. In other words, if $b$ is less than 0 , then the observer will be warned by feeling the $\mathrm{P}$ and $\mathrm{S}$ waves, and the warning will be redundant. As an example, the Tôhoku megaquake of 11 March 2011 had a blind zone of a $b=114 \mathrm{~km}$ radius around the epicenter, corresponding to a delay of $31 \mathrm{~s}$ between the origin time of the earthquake and the time the warning was issued by the new Japanese early warning system implemented in 2007.

Now, the blind zone in Japan is almost entirely offshore, and this limitation is representative of most significant Japanese earthquakes, but the recording stations, including the four stations used as data input by the system, are on land, which explains the substantial delay. The Tôhoku earthquake produced a warning of $15 \mathrm{~s}$ in advance of the arrival of the $\mathrm{S}$ waves at Sendai, arguably as good a warning as the $\mathrm{P}$ waves did, but the $S$ waves arrived half an hour to one hour ahead of the maximum tsunami waves, yet the large number of victims suggests that the early warning system failed to provide an effective warning for a sizeable segment of the population.

Consider now the case of California (Fig. 1). The white and yellow areas are blind areas of 10 to $50 \mathrm{~km}$ in diameter that happen to contain most of the population and the major earthquake sources in California, including San Francisco, San Diego, most of Los Angeles, and most of the San Andreas Fault. On the other hand, the red and dark-red areas where an early warning system could be more effective include sparsely settled regions of moderate seismicity such as the Sierra Nevada and the Mojave Desert (Fig. 1). In conclusion, an early warning system based on S-P delays may be of little use to prospective users in California, as most of them will probably receive the warning too late.

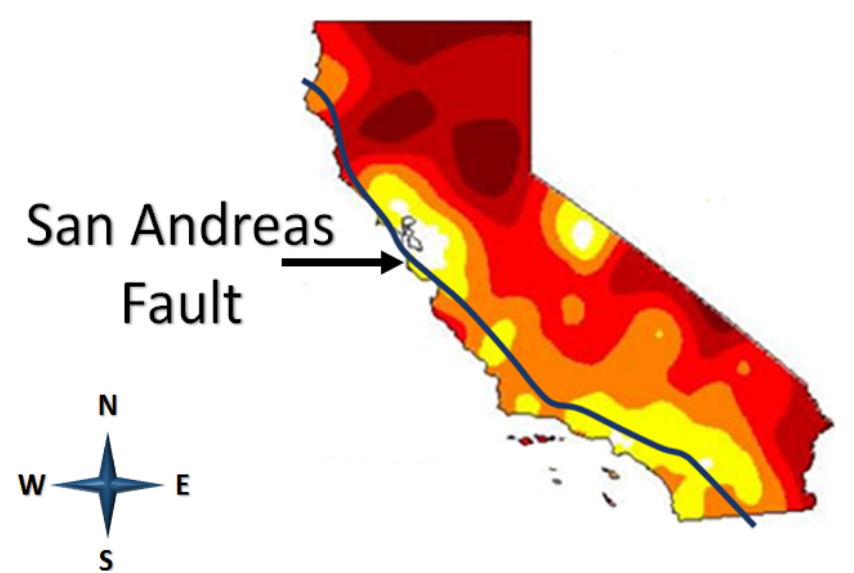

Figure 1. Blind early warning areas in California (from Kuyuk and Allen, 2013).

\section{The Tôhoku tragedy}

The 2011 Tôhoku earthquake generated the worst tsunami in the history of Japan. Tsunami sirens sounded at oceanside localities a few minutes after the earthquake, yet there were more than 18000 dead, and a survey indicated that almost half the population had neglected to withdraw to higher areas despite warnings by government.

It seems reasonable to assume that they were unaware of the impending danger to their lives. Evidently, they failed to interpret the early warning signals correctly. Konagai (2012) notes that the "overwhelming" damage and nearly all the victims were due to the tsunami, not the earthquake. The government agency Japan Meteorological Agency, which is solely authorized to issue tsunami warnings, announced a runup of 3,6 and $3 \mathrm{~m}$ for the prefectures of Iwate, Miyagi and Fukushima, respectively.

Three-meter tsunami alerts were familiar to the local people. Such alerts had been issued before, and no major tsunami had ensued. The government public relations office in Tokyo issued a story about some small children in Kamaishi (Iwate Prefecture) who bragged to their teacher "that they wouldn't evacuate if another earthquake hit the region because the adults in their families wouldn't" (mjn.gov. online.go.jp/kamaishi.html).

Early warning efficacy depends on the reliability of previous warnings. Japan has a highly informed citizenry. Kamaishi was famous for its sea wall built across the bay that failed to protect the population against the tsunami. Around 1000 people - more than $2 \%$ of the population - perished. Most of the victims $(65.2 \%)$ were 60 or older, and $46 \%$ were above 70 . On the other hand, all children that went to school at Kamaishi were safely evacuated.

The actual magnitude of the Tôhoku megaquake was $\mathrm{Mw}$ 9.0 , not 7.9, as initially announced by data centers. The error was not immediately recognized. Figure 2 shows what appears to be a standing wave along a coastal stretch of over 

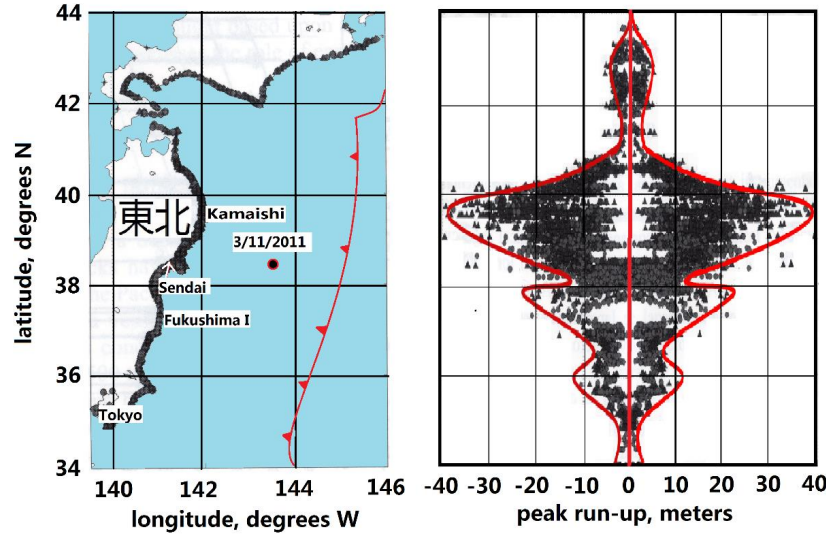

Figure 2. Left panel: Tôhoku region, Japan, with the epicenter of the 3 November 2011, Mw 9.0, megaquake and the axis of the subduction trench (yellow). Right panel: maximum runup elevations (triangles) and maximum inundations (dots), with the approximate amplitude of the standing wave (red). Tsunami Joint Survey Group, www.coastal.jp/ttjt/ (in Japanese).

$600 \mathrm{~km}$ between 35 and $41^{\circ}$ latitude north. Runup reached $40 \mathrm{~m}$ between Otsuchi and Kamaishi. This coastal area had been flooded by the 2 March 1933 Sanriku earthquake and by the 15 June 1896 Meiji-Sanriku earthquake. Finally, Otsuchi was totally destroyed in the 2011 Tôhoku tsunami. It had been relocated and rebuilt after every tsunami (Konagai, 2012).

Asai et al. (2012) found that sea walls and other "structures to reduce tsunami power" were effective in increasing resistance against tsunamis. As compared with the 2004 Indian Ocean tsunami, Japanese structures were found to survive significantly better because of the presence of structures that reduced tsunami power.

\section{Magnitude determinations}

Automation of magnitude determinations advanced rapidly after the 2004 Indian Ocean tsunami. However, some errors led to "huge underestimates of tsunami heights" (Konagai, 2012).

Clipping is a term used in seismology to describe the saturation of seismic records when ground motion exceeds the operating range of near-field seismographs (Yang and BenZion, 2010). The resulting negative skew in the magnitude is attributed to the fact that a clipped amplitude record cannot be used in magnitude estimations.

The ShakeMap automatic intensity-predictor software uses magnitude estimates as input to predict damage and casualties on a traffic-light scale (green-amber-red). Magnitude errors caused by the fact that most broadband instruments went offscale, are not automatically factored in. After the Tôhoku megaquake, the ShakeMap software was fed a magnitude of 7.9 , and it predicted "green", meaning an even chance of at most one casualty. An hour later, as data from more distant broadband stations came in, the error was corrected and the ShakeMap estimate was upgraded, first to "amber" and then to "red" (Hayes et al., 2011).

By then, thousands of people had drowned. Clipping is a common problem with broadband seismographs. Modern seismographs are sensitive instruments: they are not built to function at locations less than $50 \mathrm{~km}$ from the epicenter of a strong earthquake. This is the task of the accelerograph, an instrument used by engineers to study damaging ground accelerations. However, seismometers and accelerometers are rarely used together at the same location. Seismometers are installed at "quiet" locations, preferably on rock, while accelerographs are normally installed in engineering structures or noisy urban locations. The shaking at the site of the Fukushima Dai-ichi nuclear power station reached 0.52 to $0.56 \mathrm{~g}$, which is more than half the acceleration of gravity. This means that broadband seismographs were saturated, but accelerographs were not. The reactors were built to withstand this acceleration, and did, but they were not built to survive a prolonged station blackout.

\section{Darwin's twin-epicenter theory}

Charles Darwin, at age 26, felt the great 1835 Chile earthquake. He summarized his observations as follows: "It appears that the wave first rises in the offing; and as this is of general occurrence, the cause must be general: I suspect we must look to the line, where the less disturbed waters of the deep ocean join the water nearer the coast, which has partaken of the movements of the land, as the place where the great wave is first generated" (Darwin, 1860).

His observations were based on eyewitness reports collected in bays and coves in and around the city of Concepción, and on measurements of about 10 feet of uplift at the offshore island of Santa Maria. The epicenter could not have been far off, but there was a delay of at least half an hour between the earthquake and the arrival of the tsunami wave at coastal locations. Darwin was puzzled: the delay was too long. It should have been shorter if both phenomena had the same origin in space and in time. He boldly inferred that there were two separate epicenters, one for the earthquake and a more distant one for the tsunami. Hence his hypothesis that the tsunami arose "in the offing" - a nautical term for beyond anchoring ground, more than 10 miles offshore.

Modern data show that tsunamis do not arise at the epicenter or from splay faults that branch off the main thrust fault but at the bottom of the trench, where the continental slope joins the oceanic deep. Darwin should be credited for his insight that tsunamis are caused by bodily "movements of the land" (Fig. 3). In the 2011 Tôhoku megaquake, the line source of the tsunami was about twice as distant from the coastline as the epicenter of the earthquake. Subduction may be described as the interaction of an active plate with 


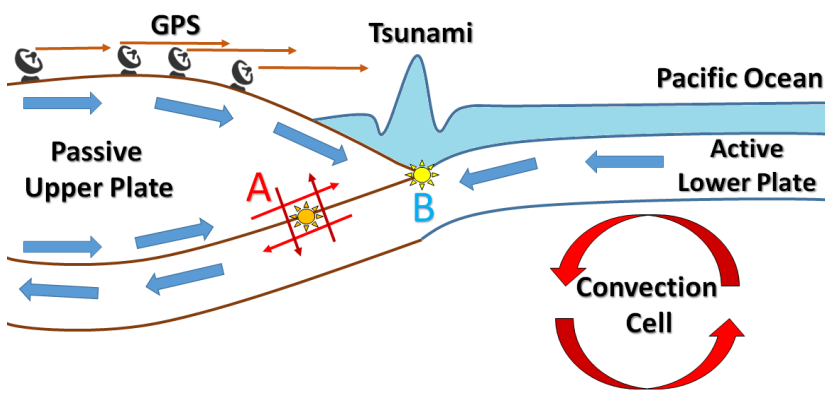

Figure 3. (a) Hypocenter of the 2011 Tôhoku earthquake; (b) axis of the trench where the recoiling upper plate generates the tsunami. The coseismic momenta of both plates must be equal and opposite.

a passive plate. According to Newton's third law, "to every action there is always opposed an equal reaction". Conservation of momentum requires that a gun recoils immediately upon firing. The total momentum is $p_{\mathrm{f}}+p_{\mathrm{r}}=0$, where $p_{\mathrm{f}}$ is the forward momentum of the bullet and $p_{\mathrm{r}}$ is the recoil of the gun. Similarly, the active plate lurches forward and under the passive plate, which impacts the ocean. In agreement with Darwin's observation, this occurs at the axis of the trench. The recoil was witnessed by all 1200 GPS stations of the GEONET network that had drifted slowly westward before the earthquake but that suddenly reversed their motion (GIA, 2011).

\section{Ergodicity}

After the 1964 Alaska megaquake (Mw 9.2), there was a four-decade lull in the incidence of megaquakes. As a result, our knowledge of megaquakes and megatsunamis began to lag "far behind the knowledge base created by basic research" (National Research Council, 2002).

A plate boundary is a dynamical system. The occurrence of large earthquakes may be represented as a phase diagram such as Fig. 4. Every point in phase space is a state in the system, where vertical lines represent ruptures along the plate boundary and blank spaces represent interseismic periods. Ruptures are followed by periods of healing (Fielding et al., 2009).

Earthquakes are followed by a healing process (blue areas) that decays exponentially in time, such that the half-life of a healing process is approximately twenty years. Healing occurs from the edge of a rupture inwards; it is discretized by aftershocks. The main shocks cannot propagate into the blue spaces, but only into segments that have healed. We propose that this system conforms to the ergodic hypothesis often assumed in statistical mechanics, namely that the average of the process equals the average of the ruptures over time.

A megaquake is a rupture that extends over three or more consecutive segments (Koper et al., 2011). The central Chile

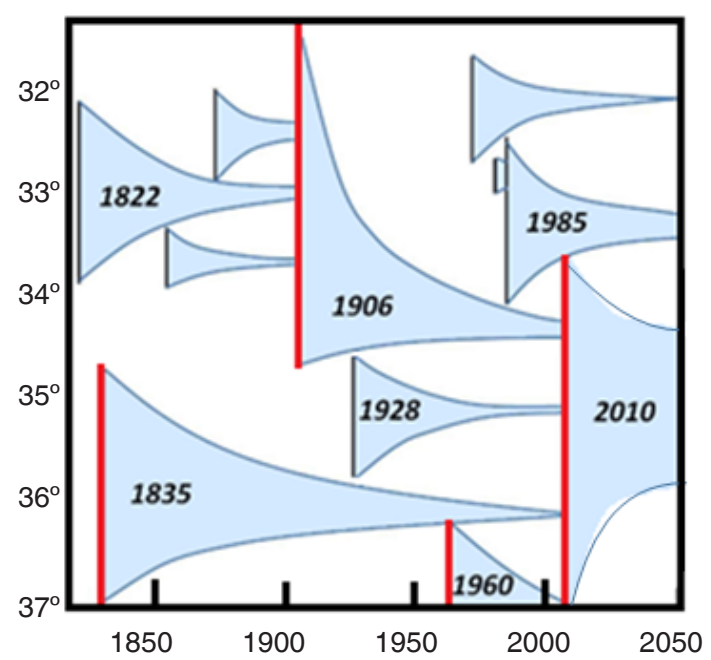

Figure 4. The south-central Chile plate boundary (1820-2050). Each megaquake (red lines) ruptured three contiguous segments in phase space.

system shown in Fig. 4 has produced three megaquakes since 1822: the 1835, 1906 and 2010 megaquakes. These events were composite, very large earthquakes that recur more frequently than they would singly (Kagan, 1997). They are highly damaging events, and national agencies are introducing early warning systems against them in cooperation with academic institutions, chiefly because megaquakes are known to generate large tsunamis, but the hazard may not have been understood fully. In the 2011 Japanese earthquake, an Mw 9 megaquake was not expected: the Tôhoku region was shown on official maps as a low-hazard region (Geller, 2011).

After every major earthquake, the plate boundary undergoes a process that may be called healing (Fielding et al., 2009). The fragmentation process of the plate boundary is random, but the healing process (blue spaces) is deterministic. Such mixed, random/deterministic processes occur frequently in stationary physical systems (Ulam, 1952; Tiampo et al., 2004). According to Jackson and Kagan (2006), the segmentation process at plate boundaries has given rise to theoretical interpretations of doubtful explanatory value, such as the occurrence of gaps and characteristic earthquakes.

John von Neumann (1932) proved that if the phase space $\Xi$ of a random process is invariant under some transformation $P \rightarrow P_{t}$ where $P$ is a point of $\Xi$ and $t$ is time, then any realization of the process over a limited period of time may contain sufficient information for estimating the parameters of the process. Von Neumann and Ulam were interested in simulating a process with a very low rate of incidence, such as a process of neutrons colliding with atoms in a fissile material (Kahn, 1956). They considered a model based on the game of Russian roulette. A revolver has $m$ chambers and a 
single chamber is loaded. If the gun is randomized by spinning the barrel before every round, the survivor function after $x$ rounds is

$S(x)=P\{$ lifetime $>x\}=\left(\frac{m-1}{m}\right)^{x}$.

The discrete time parameter $x$ may be replaced by a continuous one; then, the survivor function for large $m$ may be written as $S(x) \approx \exp (-\lambda x)$. For example, let $\lambda$ be the incidence of multiple ruptures in Fig. 4. Then, the probability of finding zero events in an interval $\tau$ is

$\operatorname{Pr}\{N(0, \tau]=0\}=e^{-\lambda \tau}$.

This is the survivor function for an interval $\tau$. If the process is stationary, Eq. (3) applies to an interval $\tau^{0}$ defined as the forward recurrence time of rare events, namely the interval from an arbitrary time origin to the next event. Three megaquakes occurred in central Chile within a period of 192 years (Fig. 4), thus, $\lambda=3 / 192=0.015625$ megaquakes per year. This expression (Eq. 3) may also be used for estimating the recurrence times of megaquakes with a very low rate of incidence.

\section{Some final reflections}

Expect the unexpected. In the 2011 Japanese earthquake, a magnitude 9 megaquake was not expected. The Tôhoku region was shown on maps of earthquake risk as a low-hazard region (Geller, 2011). The marine terraces overlooking the ocean at an elevation of $25 \mathrm{~m}$ were spurned as a location for the Fukushima nuclear power plant.

Commercial nuclear power stations were developed as an offshoot of nuclear reactors designed to power the fleet of US submarines under Admiral H. G. Rickover. The navy commissioned 168 submarines, nine cruisers, and six aircraft carriers - all nuclear powered. The navy was proud of a zeroaccident record. Unlike power plants, however, submarines are immersed in a near-infinite heat sink. They can remain submerged for months, and they are not vulnerable to fluctuations of the sea level.

Sociologist Niklas Luhmann (2003) found it "remarkable" that the realm of disaster prevention is bedeviled with deviancy, when common sense would tend to disregard outliers and to concentrate on common risks, such as being unable to make ends meet. In disaster prevention, there is a fascination with the recurrence of highly unlikely catastrophes. The 2011 Tôhoku tsunami produced a $40 \mathrm{~m}$ high standing wave, the 1960 Chile tsunami ran up to $30 \mathrm{~m}$ high, and it seems likely that similar runup values were caused by the Jôgan, Japan tsunami of 9 July 869 on the Tôhoku coast. Not only natural hazards, however: disasters in modern societies are, more often than not, caused by decisions in organizations. Hopefully, we have learned the lesson.
Acknowledgements. We thank Zhang Chaojun for his valuable suggestions and Luis D. Rodríguez Padilla and Erick Minero Reyes for their assistance in preparing the figures.

Edited by: T. Glade

Reviewed by: two anonymous referees

\section{References}

Anderson, E. M.: Dynamics of faulting, Trans. Geol. Soc. Edinburgh, 8, 387-402, 1905.

Atkinson, B. K. and Rawlings, R. B.: Acoustic emission during stress corrosion cracking in rocks, in: Earthquake Prediction: An international review, AGU Maurice Ewing Series, vol. 4, Washington, D.C., 605-616, 1980.

Bourdieu, P.: La distinction: Critique sociale du jugement, Éditions de Minuit, Paris, 672 pp., 1979.

Cabinet Office: Estimate of the total amount of suffering, Press release, 24 June 2011, http:www.bousai.go.jp/oshirase/h23/ 110624-1kisya.pdf, last access: 23 June 2014, 2011.

Castaños, H. and Lomnitz, C.: Earthquake Disasters in Latin America: A Holistic Approach, Springer, Dordrecht, 2012.

Darwin, C. R.: Journal of Researches into the Natural History and Geology of the Countries Visited during the Voyage of H. M. S. Beagle round the World under the Command of Capt., edited by: FitzRoy, R. N., John Murray, London, 1860.

Feiler, P. H.: Improving safety-critical systems with a reliability validation \& improvement framework, SEI Blog, Carnegie Mellon University, Pittsburgh, PA, 3 June 2013.

Feller, W.: An Introduction to Probability Theory and its Applications, Vol. II, 2nd Edn., John Wiley \& Sons, New York, 219 pp., 1966.

Feynman, R. P.: Personal Observations on the Reliability of the Shuttle, Rogers Commission Report, Appendix F, http://science.ksc.nasa.gov/shuttle/missions/51-1/docs/

rogers-commission/Appendix-F.txt, last access: 23 June 2014, 1987.

Fielding, E. J., Lundgren, P. R., Bürgmann, R., and Funning, G. J.: Shallow fault-zone dilatancy recovery after the 2003 Bam, Iran earthquake, Nature, 458, 64-68, doi:10.1038/nature07817, 2009.

Fisher, R. A.: On the Mathematical Foundations of Theoretical Statistics, Philos. T. Roy. Soc. Lond. A, 222, 309-368, 1922.

Geller, R. J.: Shake-up time for Japanese seismology, Nature, 472, 407-409, doi:10.1038/nature10105, 2011.

GIA - Geospatial Information Authority: Tectonic deformations caused by the March $11^{\text {th }} 2011$ off the coast of Tohoku earthquake tsunami information, Bull. GIA, 59, Tsukuba, 19 March 2011.

Hainzl, S., Steacy, S., and Marsan, D.: Seismicity models based on Coulomb stress calculations, Community Online Resource for Statistical Seismicity Analysis, Zurich, 25 pp., doi:10.5078/corssa-32035809, 2010.

Harris, R. A. and Arrowsmith, J. R.: Introduction to the Special Issue on the 2004 Parkfield earthquake and the Parkfield Prediction Experiment, B. Seismol. Soc. Am., 96, S1-S10, 2006.

Hayes, G. P., Earle, P. S., Benz, H. M., Wald, D. J., and Briggs, R. W.: 88 hours: The U.S. Geological Survey National Earthquake 
Information Center response to the 11 March $2011 \mathrm{Mw} 9.0$ Tohoku earthquake, Seismol. Res. Lett., 82, 481-493, 2011.

Jackson, D. D. and Kagan, Y. Y.: The 2004 Parkfield earthquake, the 1985 prediction, and characteristic earthquakes: Lessons for the Future, B. Seismol. Soc. Am., 96, S397-S409, 2006.

Kagan, Y. Y.: Statistical aspects of Parkfield earthquake sequence and Parkfield prediction experiment, Tectonophysics, 270, 207219, 1997.

Kahn, H.: Use of different Monte-Carlo sampling techniques, in: Symposion on the Monte-Carlo Method, edited by: Meyer, H. A., John Wiley \& Sons, New York, 1956.

Kleidon, A. and Lorenz, R. D.: Entropy production by earth system processes, in: Non-equilibrium Thermodynamics and the Production of Entropy, edited by: Kleidon, A. and Lorenz, R. D., Springer, New York, 1-20, 2005.

Knight, F. H.: Risk, Uncertainty, and Profit, Houghton Mifflin, Boston, 1921.

Koper, K. D., Hutko, A. R., Lay, T., Ammon, C. J., and Kanamori, H.: Frequency-dependent rupture process of the $2011 \mathrm{Mw} 9.0$ Tohoku Earthquake: Comparison of short-period $P$ wave backprojection images and broadband seismic rupture models, Earth Planets Space, 63, 599-602, 2011.

Kuyuk, H. S. and Allen, R. M.: Optimal Seismic Network Density for Earthquake Early Warning: A Case Study from California, Seismol. Res. Lett., 84, 946-954, doi:10.1785/0220130043, 2013.

Lipscy, P. Y., Kushida, K. E., and Incerti, T.: The Fukushima disaster and Japan's nuclear plant vulnerability in comparative perspective, Environ. Sci. Technol., 47, 6082-6088, 2013.

Lomnitz, C. and Zhang, C.: Parkfield revisited: I. Data retrieval, Lithosphere, 1, 227-234, doi:10.1130/L14.1, 2009.
Loveless, J. P., Pritchard, M. E., and Kukowski, N.: Testing mechanisms of subduction zone segmentation and seismogenesis with slip distributions from recent Andean earthquakes, Tectonophysics, 495, 15-33, doi:10.1016/j.tecto.2009.05.008, 2010.

Mikumo, T., Garces, M., Shibutani, T., Morii, W., Okawa, T., and Ishihara, Y.: Acoustic-gravity waves from the source region of the 2011 great Tohoku earthquake $(\mathrm{Mw}=9.0)$, J. Geophys. Res.Solid, 118, 1534-1545, doi:10.1002/jgrb.10143, 2013.

National Research Council: Living on an Active Earth: Perspectives on Earthquake Science, Washington, D.C., 418 pp., 2002.

Reid, H. F.: The Mechanics of the Earthquake, The California Earthquake of April 18, 1906, Report of the State Investigation Commission, Vol. 2, Carnegie Institution of Washington, Washington, D.C., 1910.

Ruff, L. and Kanamori, H.: Seismic coupling and uncoupling at subduction zones, Tectonophysics, 99, 99-117, 1983.

Scholz, C. H. and Das, S.: Subcritical rupture in the Earth, I. Physics and observations, Eos Trans. AGU, 61, 304, 1980.

Tiampo, K. F., Rundle, J. B., Klein, W., and Sá Martins, T. S.: Ergodicity in natural fault systems, Pure Appl. Geophys., 161, 1957-1968, 2004.

Ulam, S.: Random processes and transformations, in: Proc. Int. Congr. Math., Vol. 2, Cambridge, MS, 264-275, 1952.

Von Neumann, J.: Physical Applications of the Ergodic Hypothesis, P. Natl. Acad. Sci. USA, 18, 263-266, 1932.

Yang, W. and Ben-Zion, Y.: An algorithm for detecting clipped waveforms and suggested correction procedures, Seismol. Res. Lett., 81, 53-62, 2010. 